\title{
Depoimento Especial: Para Além do Embate e pela Proteção das Crianças e Adolescentes Vítimas de Violência Sexual
}

\author{
Cátula Pelisoli ${ }^{1}$ \\ Universidade Federal do Rio Grande do Sul, Porto Alegre, Rio Grande do Sul, Brasil \\ Faculdade Cenecista de Osório, Osório, Rio Grande do Sul, Brasil \\ Veleda Dobke \\ Ministério Público do Rio Grande do Sul, Porto Alegre, Rio Grande do Sul, Brasil \\ Débora Dalbosco Dell'Aglio \\ Departamento de Psicologia do Desenvolvimento e da Personalidade da Universidade \\ Federal do Rio Grande do Sul, Porto Alegre, Rio Grande do Sul, Brasil
}

\begin{abstract}
Resumo
A nova metodologia de inquirição de crianças e adolescentes vítimas de abuso sexual pelo Poder Judiciário denominada Depoimento Especial tem sido discutida por profissionais de diferentes áreas do conhecimento. Dessas discussões, resultaram opiniões divergentes sobre o assunto. Esse artigo visa apresentar historicamente a metodologia do Depoimento Especial, primeiramente denominado Depoimento Sem Dano, e discutir as necessidades de a Justiça dialogar com outros saberes para um melhor direcionamento da realização deste ato processual - a ouvida da criança. Conclui-se, a partir da revisão de literatura e da interlocução entre Psicologia e Direito, que as discordâncias e debates legais não têm contribuído para a proteção das vítimas. O Poder Judiciário e outras áreas do conhecimento precisam fortalecer suas habilidades para trabalhar em conjunto numa interlocução respeitosa e equânime troca de conhecimentos. A realização da nova metodologia é possível e necessária, entretanto, mudanças podem trazer benefícios e maior proteção a crianças e adolescentes brasileiros.
\end{abstract}

Palavras-chave: Depoimento especial, depoimento sem dano, inquirição, abuso sexual, Psicologia Jurídica.

\section{Special Testimony: Beyond Legal Conflicts and in Favor of the Protection of Children and Adolescents Victims of Sexual Violence}

\begin{abstract}
The Judiciary Inquiry method of testimony for children and adolescents who suffered sexual abuse, called special testimony, has been discussed by professionals and there are divergent opinions about it. This article aims to present historically the Special Inquiry method that has been used in Brazil, firstly named Testimony without Damage, and discuss the needs of the area for a better direction of this activity. The

Endereço para correspondência: Departamento de Psicologia do Desenvolvimento e da Personalidade, Instituto de Psicologia, Universidade Federal do Rio Grande do Sul, Rua Ramiro Barcelos, 2600, sala 115, Porto Alegre, RS, Brasil, 90035-003. E-mail: catulapelisoli@yahoo.com.br, veledadobke@uol.com.br e dalbosco@cpovo.net Apoio financeiro: Trabalho realizado com apoio do Conselho Nacional de Pesquisa e Desenvolvimento Científico e Tecnológico - CNPq Brasil.
\end{abstract}


conclusions from the literature review and interlocution between Psychology and Law show that these legal and technical disagreements seem not to be working in children's favor. The area needs to reinforce the abilities to work together in a respectful dialogue with an equitable knowledge exchange. The practice of the special testimony is possible and necessary, however some changes can bring benefits and greater protection for Brazilian children and adolescents.

Keywords: Special testimony, testimony without damage, inquiry, sexual abuse, Forensic Psychology.

\section{Tomada de Testimonio Especial: Para Allá de la Oposición y por la Protección de Niños y Adolescentes Víctimas de Violencia Sexual}

\section{Resumen}

La nueva tecnología de escucha de niños y adolescentes víctimas de abuso sexual por el Poder Judicial denominada Tomada de Testimonio Especial es tema de discusión de profesionales de distintas áreas del conocimiento. De esas discusiones resultaron opiniones divergentes acerca del asunto. Este artículo busca presentar históricamente la metodología de la Tomada de Testimonio Especial, primeramente denominada Testimonio Sin Daño, y discutir las necesidades de que la Justicia dialogue con otros saberes para una mejor dirección en la realización de este acto procesual - la escucha de niños. Se concluye, partiendo de la revisión de literatura y de la interlocución entre Psicología y Derecho, que las discordancias y debates legales no contribuyen para la protección de las víctimas. El Poder Judicial y otras áreas del conocimiento necesitan fortalecer sus habilidades para trabajar en conjunto en una interlocución respetuosa y ecuánime cambio de conocimientos. La realización de la nueva tecnología es posible y necesaria, sin embargo, cambios pueden traer beneficios y mayor protección a los niños y adolescentes brasileños.

Palabras clave: Tomada de testimonio especial, testimonio sin daño, escucha, abuso sexual, Psicología Jurídica.

O abuso sexual, entendido como "o envolvimento de uma criança em uma atividade que ela não compreende totalmente, para a qual não tem habilidade de dar consentimento ou não está fisicamente preparada ou ainda que viole leis e tabus da sociedade" (World Health Organization [WHO], 2006, p. 10), é um problema social que atinge milhões de crianças e adolescentes no mundo (Trickett, Negriff, Ji, \& Peckins, 2011). Essa forma de maus tratos contra crianças e adolescentes é definida também como uma atividade que objetiva prover prazer, estimulação ou gratificação sexual a um adulto, que usa uma criança para este propósito, tirando vantagem de sua posição dominante. É considerado abuso sexual quando existe uma relação assimétrica entre a vítima e o agressor, que pode se apresentar de diferentes formas. Uma forma de assimetria é a diferença de idade: uma diferença de cinco anos de idade quando a criança é menor de 12 anos e de dez anos quando é maior de 12 anos caracteriza uma relação assimétrica. Outra forma é quando existe diferença de poder, como quando o agressor tem controle ou autoridade sobre a vítima, ou ainda quando há conhecimento ou habilidades sociais diferenciadas, que se exemplifica quando o agressor usa suas habilidades para manipular a vítima (Sanchez-Meca, Rosa-Alcázar, \& López-Soler, 2011).

O abuso sexual contra crianças e adolescentes ou abuso sexual infantil - ASI tem sido prevalente em todas as partes do mundo e tem sido considerado como uma das mais graves infrações aos direitos humanos (El-Sayed Aboul-Hagag \& Hamed, 2012). Recente estudo investigando a prevalência internacional deste problema através de uma meta-análise envolvendo 65 artigos de 22 países encontrou médias de 7,9\% para homens e de 19,7\% para mulheres (Pereda, Guilera, Forns, \& Gomez-Benito, 2009). Uma estima- 
tiva global de $11,8 \%$ foi determinada por outra importante análise que considerou 217 estudos, incluindo 9.911 .748 participantes (Stoltenborgh, Van Ijzerdoorn, Euser, \& Bakermans-Kranenburg, 2011). Segundo a WHO (2010), em torno de $20 \%$ das mulheres e entre $5-10 \%$ dos homens relatam ter sido sexualmente abusados em sua infância. No Brasil, as estatísticas apontam crescimento das denúncias de abuso sexual (Secretaria de Direitos Humanos da Presidência da República, 2010), demonstrando que esse é um fenômeno que atinge milhares de pessoas também em nosso país e que requer estudos para melhor conhecer o problema e medidas para dar conta das consequências nefastas que ele pode produzir. Essas consequências incluem desde sentimentos de medo, ansiedade, pesadelos, prejuízos no desempenho acadêmico, até o desenvolvimento de psicopatologias como transtorno de estresse pós-traumático, depressão, transtornos por uso de substância, entre outros (Myers, 2006; Paolucci, Genius, \& Violato, 2001).

Há consenso, na literatura, sobre a diferença entre a quantidade de casos de abusos sexuais que realmente ocorrem e a quantidade que chega ao conhecimento das autoridades judiciárias (Miller-Perrin \& Perrin, 2013). Muitos casos parecem permanecer presos nos muros de silêncio dos lares abusivos, caracterizando então o que se chama de um crime subnotificado: ou seja, ele ocorre mais do que é formalmente conhecido (Miller-Perrin \& Perrin, 2013). Além de pouco notificado, aqueles casos que o são, poucas vezes chegam à punição do agressor. Esse caminho a ser percorrido inicia com a revelação da vítima e judicialmente se encerra com a sentença (Dobke, Santos, \& Dell'Aglio, 2010). Mas várias etapas entre essas duas extremidades são necessárias, a saber: (a) revelação por parte da vítima e comunicação da família, cuidadores ou da própria vitima a órgão ou profissional; (b) notificação compulsória, que é o comunicado formal ao Conselho Tutelar ou outra autoridade da suspeita ou ocorrência do abuso pelo profissional responsável, com preenchimento de uma ficha padronizada de notificação (Ministério da Saúde, 2001); (c) investigação; (d) denúncia, que é a peça que inicia o processo penal, oferecida pelo Promotor de Justiça ao Juiz de Direito; (e) demais atos do processo penal, que visa à responsabilização do agressor, como por exemplo, a defesa do acusado, a instrução do processo, as alegações escritas e a sentença (Dobke et al., 2010; Lima \& Deslandes, 2011; Saliba, Garbin, Garbin, \& Dossi, 2007). Neste caminho, a vítima deve, em diferentes ocasiões, expor a violência sofrida. A palavra da vítima é especialmente importante em casos com elementos contraditórios (Finnila-Tuohimaa, Santilla, Sainio, Niemi, \& Sandnabba, 2009), como ocorre na maioria das situações de ASI.

Nesse sentido, tem sido realizado um esforço, em diversos países, para que a vítima seja menos prejudicada possível com as intervenções que ocorrem ao longo do processo legal. Uma das estratégias que buscam minimizar o sofrimento e diminuir a quantidade de momentos que a vítima precisa falar sobre o evento traumático é a tomada de Depoimento Especial. Durante a instrução do processo, a coleta de dados com a vítima deve ser realizada sob a vigência dos princípios constitucionais do contraditório e da ampla defesa. Trata-se do depoimento da vítima no contexto processual, o que difere do contexto pré-processual, onde não há ainda a garantia do devido processo legal por não estarem vigentes os princípios antes referidos. Esse artigo visa apresentar a metodologia de inquirição de crianças e adolescentes vítimas no contexto do Poder Judiciário atualmente denominada "Depoimento Especial”, esclarecendo as especificidades observadas por ambas as áreas - Psicologia e Direito para a condução dessa intervenção judicial. Para isso, uma revisão integrativa de metodologias similares ao Depoimento Especial e resultados conquistados em outros países será apresentada, bem como o histórico, descrição do procedimento do Depoimento Especial no Brasil e sugestões para sua qualificação serão abordadas.

\section{Tomada de Depoimentos com Crianças e Adolescentes em Outros Países}

Em 1992, Goodman e colaboradores identificaram como pode ser assustador para uma criança relatar a violência sofrida na frente de seu perpetrador. Medo, raiva, revivência e outros 
sentimentos negativos foram relatados por vítimas que testemunharam em frente a réus e seus advogados. Olhares, expressões e perguntas destas duas figuras da sala de audiências tornavam o momento mais tenso e estressante e cuidadores não abusivos solicitavam mudanças no sistema de coleta de dados com crianças e adolescentes vítimas. As próprias crianças, neste estudo, indicaram que algumas das mudanças poderiam ser a retirada do réu da sala de audiências, o uso de vídeos e maior limite para as perguntas direcionadas a elas (Goodman et al., 1992).

Para minimizar esse sofrimento e o prejuízo decorrente dele, experiências alternativas de tomada de depoimentos de crianças e adolescentes têm sido realizadas em diversos países. Em um mapeamento realizado por B. R. Santos e Gonçalves (2009), foram identificadas experiências nos cinco continentes, em 25 países. A maior parte encontra-se na América do Sul (28\%), Europa (28\%) e Ásia (16\%). Os países da América do Sul que têm realizado o Depoimento Especial são Argentina, Brasil, Chile, Colômbia, Equador, Paraguai e Peru. Especialmente, a Argentina tem sido considerada um país referência. A adoção de práticas investigativas, através da Câmara de Gesell, ocorre nas instalações do Tribunal ou do Ministério Público, onde o psicólogo forense facilita o diálogo entre a vítima, o juiz, o defensor do acusado e o promotor de justiça. O depoimento é colhido apenas por psicólogos treinados e conhecedores dos temas relativos à Psicologia Jurídica e técnicas cognitivas/investigativas. Outro país de referência é a Inglaterra, onde os depoimentos são geralmente tomados, na fase investigativa, por policiais capacitados. Entretanto, apesar de ser realizado por policiais, o depoimento não é tomado em delegacia comum. Esse procedimento ocorre em outras unidades policiais, em salas especiais, com diversos cuidados para com a criança e para com a produção da prova: um ambiente mais confortável e amigável para a criança e um local fechado, sem a presença de ruídos, com câmeras em diferentes ângulos e microfones perto do sofá onde senta a vítima. A sala também é equipada com um interfone, que servirá para a comunicação do policial que está ouvindo a vítima com o policial que opera os equipamentos e que pode realizar alguma intervenção (B. R. Santos \& Gonçalves, 2009).

A tomada de depoimentos tem utilizado duas abordagens: Closed Circuit Television (CCTV) e Câmara de Gesell. A maior parte dos países (64\%) utiliza o sistema CCTV, que coleta depoimentos por meio de um circuito fechado de televisão e de videogravação. Os outros 34\% dos países utilizam a Câmara de Gesell, que utiliza duas salas divididas por um espelho unidirecional (B. R. Santos \& Gonçalves, 2009). No Brasil, tem sido utilizado o primeiro sistema. Com relação aos locais de coleta dos depoimentos, na maioria dos países $(48 \%)$, as salas estão localizadas na estrutura da polícia (para a produção antecipada de provas) e também nos tribunais (para os casos que vão a julgamento). Entretanto, essas salas podem estar também no Ministério Público, no Poder Executivo (como no caso da França que possui salas em hospitais) e até em Organizações Não-Governamentais (como na Lituânia). Os responsáveis pela tarefa de tomar o depoimento podem ser psicólogos, policiais, médicos, assistentes sociais, psicopedagogos, promotores de justiça, juízes de direito, entre outros (B. R. Santos \& Gonçalves, 2009).

Nos Estados Unidos, serviços que coordenam ações na investigação do abuso sexual têm obtido resultados interessantes (Cross, Jones, Walsh, Simone, \& Kolko, 2007). Estes serviços reúnem diferentes órgãos, representados pelos respectivos profissionais, em um espaço único e, através de um profissional especializado, realizam entrevistas com as crianças e adolescentes vítimas, bem como com suas famílias. Este profissional, geralmente um policial treinado, é acompanhado na entrevista, através do sistema CCTV, por outros agentes com pleno conhecimento do caso. A ênfase no compartilhamento de informações entre todos os profissionais contribui para que o caso seja conhecido por todos e para que uma tomada de decisão conjunta possa ser realizada mais adequadamente (Children Justice Center [CJC], 2009). Além disso, o compartilhamento de informações contribui para a redução do número de entrevistas, tendo como consequência a minimização do trauma, uma vez que, aqueles que devem decidir sobre o caso, previamente assistem à entrevista, têm acesso à 
gravação e discutem o caso de forma multidisciplinar. O CJC, por exemplo, procura utilizar as melhores práticas existentes para a investigação, manejo do caso, tratamento e para as questões de ordem legal, num sistema coordenado e multidisciplinar para responder aos casos de abuso sexual, abuso físico grave e crianças testemunhas de crimes violentos (CJC, 2009).

Neste mesmo sentido, o Children's Advocacy Center (CAC) tem como objetivo a qualificação de entrevistas forenses com crianças que estão envolvidas em situações de abuso sexual (Cross et al., 2007). Ambos os serviços (CJC e CAC) fazem parte da National Children's Alliance, que é uma organização profissional destinada a ajudar comunidades a lidar com alegações de abuso de uma forma eficiente, a partir de treinamentos, suporte, liderança e assistência técnica nos casos de abuso contra crianças e adolescentes (National Children's Alliance, 2012). A proposta do serviço é a utilização de apenas um entrevistador que provê as informações para todos os outros investigadores envolvidos no caso, num serviço coordenado de agências relacionadas à justiça, à proteção e outros serviços. O lugar onde a entrevista é realizada é diferente de um estabelecimento policial, escolar ou de proteção. O espaço é neutro, amigável, com privacidade e livre de distrações (Cross et al., 2007). Para investigar possíveis diferenças entre serviços utilizando essa proposta de coordenação multidisciplinar e serviços que não a utilizam, Cross et al. (2007) investigaram 1.069 casos de abuso sexual e abuso físico (84\% ASI). O estudo comparativo demonstrou que os serviços que seguem as propostas da National Children's Alliance apresentam menor número de entrevistas com a vítima (uma ou no máximo duas), maior número de reuniões para discutir os casos, maior número de reuniões de equipe, maior coordenação/participação de diferentes agências no caso, eram mais prováveis de ter apenas um entrevistador conduzindo todas as entrevistas e também de essa entrevista acontecer em um ambiente amigável. Os resultados, encontrados nestes serviços, apontam para experiências mais positivas para as crianças e famílias.

Formas tradicionais e alternativas de depoimento também foram comparadas no estudo de
McAulif e Kovera (2012). Os autores basearam-se na opinião de jurados sobre as formas diferentes de depoimento com supostas vítimas de diferentes idades e histórias de violência. Os resultados indicaram que os jurados esperam que uma criança, num depoimento tradicional, sinta-se mais nervosa, chorosa, inquieta, menos confiante, cooperativa, fluente, que mantenha menos contato ocular e dê respostas mais curtas. Na Nova Zelândia, um dos países pioneiros na utilização de formas alternativas de tomada de depoimentos, foram observados benefícios em relação à obtenção de uma melhor qualidade da evidência e eficiência nos processos jurídicos (Hanna, Davies, Crothers, \& Henderson, 2012). Estudos anteriores também apontaram resultados positivos do uso do CCTV como o fato de as crianças estarem mais relaxadas e proverem depoimentos mais detalhados e completos (Goodman et al., 1998). É provável que o fato de não encontrar o perpetrador atue como um importante aspecto, uma vez que este é o maior medo de crianças vitimas (Goodman et al., 1992). Portanto, não é somente em estudos atuais que é possível encontrar bons motivos para o uso de circuitos televisivos para a tomada do testemunho de crianças e adolescentes, mas também em trabalhos mais remotos, que já consideravam esses métodos como mais protetivos para as vítimas (Scott, 1994).

\section{A Necessidade da Tomada de Depoi- mento da Criança e do Adolescente na Justiça Brasileira}

O abuso sexual é uma das formas mais graves de maltrato infanto-juvenil e viola um dos princípios fundamentais da Constituição Federal, qual seja o da dignidade da pessoa humana (Constituição da República Federativa do Brasil de 1988 [CF]). Atenta, então, contra os direitos humanos das crianças e adolescentes, pois, como sujeitos de direito que são, lhes é garantido o desenvolvimento sem violência, competindo à família, à comunidade, à sociedade em geral e ao poder público assegurar a efetivação desses direitos (Estatuto da Criança e do Adolescente [ECA], 1990). A violação da dignidade da criança e do adolescente, principalmente, no caso do 
abuso sexual, exige a intervenção destes atores para atender/proteger a vítima e também punir o agressor.

No caso da intervenção judicial, é sempre necessária a propositura de uma ação, de natureza cível ou penal, dependendo do objetivo que se busca (Código de Processo Civil, 1973; Código de Processo Penal, 1941). Para a suspensão do poder familiar, por exemplo, a ação é de natureza cível, podendo ser proposta pelo Promotor de Justiça ou por representante legal da vítima. Para a responsabilização penal do agressor, a ação é penal e quem a propõe é o Promotor de Justiça. Somente com a comprovação da prática abusiva, é que as medidas de proteção à vítima $\mathrm{e}$ de sanção ao réu serão impostas. O suposto abusador, no exemplo dado, comprovado o fato e a sua autoria, terá suspenso o poder familiar e será responsabilizado penalmente.

Com relação ao processo que visa à responsabilização penal do suposto agressor, este tem assegurado, constitucionalmente, o devido processo legal, ou seja, não poderá ser acusado sem que lhe seja garantido o contraditório e a ampla defesa (CF, 1988). Isso significa que o agressor/ denunciado tem o direito de rebater, contradizer, sempre, todas as imputações que o Promotor de Justiça lhe fizer e que ele poderá se valer de todas as provas lícitas, amplamente, para provar a sua inocência. Então, na ação judicial proposta, quando da produção da prova - momento da instrução do processo, no qual se busca a verdade fática, a comprovação da prática do abuso sexual se faz necessária para que as intervenções judiciais, de natureza cível ou penal, sejam possíveis. A convicção do juiz vai se basear na prova que foi apresentada no processo, buscando a verdade real dos fatos. A necessidade de verificar se o alegado objetivamente ocorreu é condição para que uma medida judicial seja aplicada (Código de Processo Civil, 1973; Código de Processo Penal, 1941). Se o fato abusivo alegado não for comprovado, nenhuma medida será aplicada que implique em violação de um direito do suposto abusador, como por exemplo, a suspensão do poder familiar, podendo ele conviver normalmente com a vítima.

Dessa forma, a necessidade de comprovação da prática abusiva garantirá o respeito aos direi- tos tanto do suposto abusador quanto da vítima. A criança/adolescente tem o direito de ser ouvida em todos os processos nos quais forem discutidos seus interesses (Decreto 99.710, 1990; ECA, 1990; Lei 12.010, 2009), assim como ocorre com todas as vítimas de crimes graves. Este, portanto, é o motivo mais importante para justificar o depoimento judicial da criança vítima de abuso sexual. Tanto o ECA (1990) quanto a Convenção sobre os Direitos da Criança (Decreto $99.710,1990)$ enfatizam o direto de a criança e/ou adolescente serem ouvidos. Em todo o processo judicial ou administrativo em que houver interesses desses sujeitos de direito deve ser oportunizada a sua oitiva. A ouvida da criança é um direito que ela tem e sua opinião deve ser devidamente considerada pela autoridade judiciária (Decreto 99.710, 1990; ECA, 1990). Contudo, direito não se confunde com obrigação. A obrigação de depor se impõe, como regra, somente aos adultos plenamente capazes (Código de Processo Penal, 1941). As crianças, portanto, podem exercer, ou não, este direito. Logo, não estão obrigadas a depor.

O testemunho da criança tanto pode comprovar a ocorrência do abuso sexual, como pode ser prova de que o fato não ocorreu. O próprio denunciado pela prática do fato abusivo pode requerer, como prova da sua inocência, o depoimento da vítima - nos casos de falsa imputação do abuso sexual, e tal prova não lhe poderá ser negada face ao princípio da ampla defesa (CF, 1988). O que se quer dizer é que, neste caso, o juiz não poderá indeferir o pedido de produção dessa prova, sob pena de cerceamento de defesa do acusado, o que torna nulo o processo (Código de Processo Penal, 1941). Mas, a fala da criança/ adolescente só ocorrerá se ela quiser. Isso significa que o juiz não pode negar o direito do réu, mas a vítima pode se negar a depor. Em resumo, sem ser oportunizada a oitiva da vítima, pode não haver garantia aos direitos do acusado, tampouco aos direitos da vítima de ser ouvida.

$\mathrm{O}$ fato subjacente à intrigante questão da dificuldade de articulação entre Direito e Psicologia reside em que tais disciplinas abordam diferentes aspectos do "real". Enquanto o Direito Penal, nos casos de condenação, precisa de certezas para formar a convicção do juiz so- 
bre o fato e sua autoria em processos criminais, para a Psicologia é suficiente uma verdade dita subjetiva. O princípio da verdade real (Guedes, 2012) ou da verdade material/histórica (Oliveira, 2009), característico do processo penal, busca a verdade que mais se aproxima com a realidade, com o que realmente aconteceu. Já para a Psicologia, é possível falar muito mais em probabilidades do que em certezas absolutas, considerando a complexidade biopsicossocial do ser humano. Aí residem as dificuldades de diálogo entre estes saberes, onde um (Direito) demanda respostas para um outro (Psicologia) que não encontra subsídios para responder da forma como o primeiro gostaria, pois são frequentes a ausência da materialidade (Rios, 2009) e a presença da incerteza (Finnila-Tuohimaa et al., 2009) nestes crimes. Entretanto, mesmo enfrentando a dificuldade da complexidade humana, da complexidade do crime do abuso sexual e da avaliação destes casos, a Psicologia apresenta, sem dúvida, muitos recursos avaliativos e é uma das mais importantes e requisitadas profissões para avaliar estas situações. O Depoimento Especial, portanto, constitui-se como espaço também complexo, de interação e interlocução entre essas áreas, mas onde a Psicologia pode contribuir com seu saber para a formação da convicção do juiz a respeito do caso sob julgamento e este, por sua vez, vai tomar decisões que afetam a todos os envolvidos: vítima, agressor, familiares, sempre na busca do melhor interesse da criança (ECA, 1990) e da garantia dos direitos humanos (CF, 1988). Em não havendo a oitiva da criança sob a forma do Depoimento Especial, haverá em audiência tradicional (Dobke, 2001), sendo, portanto, um retrocesso no processo de busca de melhores condições de ouvida.

\section{Depoimento Sem Dano, Depoimento Especial: História e Embate no Brasil}

No Brasil, historicamente, o depoimento de crianças, em juízo, sempre se realizou da mesma forma como ocorre com os adultos, sem quaisquer normas ou procedimentos específicos (Dobke, 2001). As normas processuais que disciplinam a oitiva de crianças são, até os dias de hoje, as mesmas que regem a inquirição de adultos, mesmo tendo as crianças condições peculiares de desenvolvimento. Entretanto, segundo Dobke (2001), ouvir crianças vítimas de abuso sexual é uma tarefa de maior complexidade, tendo em vista, especialmente, a falta de conhecimento da dinâmica da violência e o despreparo emocional dos inquiridores. Na obra da referida autora, casos de inquirição de vítimas de abuso sexual infantil foram descritos e analisados, apresentando inúmeras dificuldades e inadequações acerca do modo como este procedimento vinha sendo realizado. Relata Dobke (2001), que na ouvida da vítima, muitas vezes o réu era/é retirado da sala de audiências para não causar constrangimentos, mas isso não era/é uma regra. A coleta do testemunho se dá, nesse procedimento tradicional, na sala de audiências, tradicionalmente em forma de U, entre cujos lados se senta a criança. A vítima, portanto, está em frente ao Juiz, numa posição mais baixa e na presença do Promotor de Justiça e do Defensor. Os casos analisados pela autora mostraram dificuldades dos inquiridores em estabelecer um vínculo de confiança com a criança, dificuldades na elaboração das questões sobre o abuso, bem como no uso de linguagem adequada e de técnicas especiais para a ouvida, como a desdramatização e a expressão de licença e permissão para o relato que deve ser concedida à criança. Essas inadequações acabam por dificultar o cumprimento do objetivo do depoimento que seria a coleta do relato do fato (Dobke, 2001). Além disso, essa prática convencional de tomada de depoimentos pode levar à revitimização das crianças e adolescentes, por fazer com que eles tenham que rememorar seu sofrimento (B. R. Santos \& Gonçalves, 2009).

É recente, portanto, a preocupação com a oitiva especial da criança, considerando sua condição de desenvolvimento. Tomar declarações de forma inadequada pode causar danos àqueles que já foram prejudicados pela violência (Dobke, 2001). Nesta obra, a referida autora propõe o uso do que ela chama de "intérprete", um profissional habilitado que tenha mais condições do que os operadores do Direito de fazerem os questionamentos adequados à criança vítima. Além da proposta de um profissional "intérprete", a autora menciona a utilização da Câmara de Gesell ou sala com espelho unidirecional, o 
que permite aos operadores acompanhar o depoimento da criança e até mesmo intervir através de intercomunicadores. Foi a partir deste trabalho que surgiu, então, o projeto pioneiro do "Depoimento Sem Dano", que propõe retirar as crianças e adolescentes vítimas de abuso sexual do ambiente formal da sala de audiências e transferi-las para uma sala especialmente projetada, com recursos audiovisuais (Daltoé Cezar, 2007; Senado Federal, 2007). A dificuldade dos operadores do Direito de conduzir entrevistas com essa população foi um propulsor dessa ideia e, portanto, a presença de técnicos preparados para essa tarefa seria fundamental para colocá-la em prática. Esses técnicos poderiam assim evitar perguntas inapropriadas e, por vezes, até agressivas. Os três principais objetivos do projeto são: (a) a redução do dano à criança e ao adolescente vítima; (b) a garantia dos direitos, proteção e prevenção; e (c) melhoria da produção da prova produzida (Daltoé Cezar, 2007). A experiência do "Depoimento Sem Dano", portanto, iniciou no Brasil na Vara da Infância e Juventude de Porto Alegre - Rio Grande do Sul, em 2003, e atualmente é uma recomendação do Conselho Nacional de Justiça (2010).

No Brasil, o tema tem gerado uma série de calorosas discussões. Parecem existir dois divergentes pontos de vista sobre o assunto: aqueles que estão a favor e defendem vigorosamente o Depoimento Especial e, de outro lado, aqueles que são desfavoráveis e parecem não concordar com nenhum aspecto dessa metodologia. Por ter envolvido diretamente assistentes sociais e psicólogos nesta tarefa, o Depoimento Especial foi e continua sendo alvo de duras críticas originadas dos conselhos das duas categorias profissionais. Em 2009, o Conselho Federal de Serviço Social (CFESS) lançou uma resolução mostrando-se contrário à metodologia do então chamado Depoimento Sem Dano. A Resolução 554/2009 não reconhece a metodologia como atribuição ou competência do assistente social e responsabiliza, disciplinar e eticamente, àqueles profissionais que vincularem o título de assistente social a essa prática. Neste mesmo direcionamento, o Conselho Federal de Psicologia (CFP) lançou em 2010 a Resolução 010, regulamentando a escuta de crianças e adolescentes envolvi- dos em situações de violência (CFP, 2010). Neste documento, o Conselho entende que a escuta psicológica consiste em oferecer lugar e tempo para a expressão das demandas e desejos da criança ou adolescente. Para realizar essa escuta, o profissional deverá considerar o contexto social, histórico e cultural, respeitar a diversidade, preservar o sigilo e trabalhar em rede. O Conselho também enfatiza que o psicólogo não deve se subordinar a outras categorias profissionais e que deve ter autonomia em seu trabalho. Por fim, o documento pró́be ao psicólogo o papel de inquiridor de crianças e adolescentes em situações de violência.

Revisando as conflitivas sobre o tema, Brito (2008) aponta que na situação do depoimento, o psicólogo não teria como objetivo realizar avaliação psicológica, encaminhar ou atender, mas apenas inquirir, sendo, portanto, tarefa que está distante daquelas tradicionalmente exercidas por psicólogos. Neste trabalho, a autora refere que não há tempo para entrevistar familiares, abusador ou realizar estudo psicológico sobre o caso e que a dinâmica familiar seria desconsiderada. Outras razões citadas por Brito incluem a diferença entre o que se define por uma verdade subjetiva/psicológica e uma verdade objetiva, que seria o objeto de interesse jurídico. Além disso, a autora relata que o direito da criança de testemunhar tem se tornado um dever, na medida em que o Depoimento Especial se torna uma obrigatoriedade e a criança deve responder ao solicitado (Brito \& Pereira, 2012), o que seria, portanto, diferente de poder responder.

Entretanto, apesar das opiniões diferentes, em agosto de 2010, foi impetrado, pelo Estado do Rio Grande do Sul, o mandado de segurança 5017910-94.2010.404.7100/RS contra o Conselho Regional de Psicologia da $7^{\text {a }}$ região - CRP/ RS e contra o CFP, objetivando a suspensão da resolução número 10/2010. Da mesma forma, havia sido impetrado outro mandado de segurança, em novembro de 2009, com relação à resolução do Conselho Federal de Serviço Social (número 2009.71.00.031114-1/RS). Ambos os mandados de segurança garantiram aos profissionais da Psicologia e do Serviço Social a atuação na metodologia do Depoimento Especial, assegurando o exercício de suas profissões, conforme precei- 
to constitucional (CF, 1988). Assim, os referidos conselhos ficaram impedidos de aplicar quaisquer penalidades a estes profissionais no Estado do Rio Grande do Sul.

Antes da decisão final no mandado de segurança contra o Conselho Federal de Psicologia, o Presidente do Conselho Nacional de Justiça (CNJ), em novembro de 2010, com base no artigo 227 da CF; na Convenção Sobre os Direitos da Criança, em seu artigo 12; e no ECA, recomendou aos tribunais a criação de serviços especializados para a escuta de crianças e adolescentes vítimas ou testemunhas de violência, nos moldes do projeto Depoimento Sem Dano. No entanto, no texto da recomendação é utilizada a nomenclatura Depoimento Especial. Após essa recomendação, a Resolução CFP 10/2010 foi suspensa em outros estados, como Acre, Sergipe, Pernambuco e Mato Grosso, mas novas audiências e reuniões ainda são demandadas pelo Conselho Federal de Psicologia (CFP, 2012).

Nessa direção, o Ministério Público Federal e o Ministério Público do Estado do Rio de Janeiro ingressaram com a ação civil pública 0008692-96.2012.4.02.5101, com pedido de liminar, em face do Conselho Federal de Psicologia e do Conselho Regional de Psicologia do Rio de Janeiro, objetivando a suspensão da aplicação e dos efeitos da Resolução CFP 10/2010 em todo o território nacional. A liminar foi deferida, garantindo aos psicólogos a atuação na inquirição e impedindo que o Conselho aplique penalidades a estes profissionais. A ação antes referida encontra-se em tramitação. Com o julgamento definitivo desta ação civil pública, ficará indiscutível se os profissionais podem, ou não, atuar na escuta de crianças e adolescentes junto ao Poder Judiciário.

\section{Para Além do Embate e pela Prote- ção das Crianças e Adolescentes: Considerações Finais}

Ultrapassar a dicotomia (Brito \& Parente, 2012) existente na discussão sobre a inquirição judicial de crianças e adolescentes é essencial e não tem sido tarefa fácil, tampouco buscada pelos diferentes teóricos ou profissionais que atuam na área. $\mathrm{O}$ que parece ter se estabelecido são duas posições contrárias que atacam e defendem seus argumentos, desconsiderando as críticas e os apontamentos daqueles que estão do outro lado. Fato é que a escuta especial das crianças em juízo já está recomendada e vem sendo utilizada em vários estados do Brasil. Embora a nulidade da resolução 10/2010 não tenha, ainda, abrangência nacional definitiva, pois apenas concedida liminarmente, a validade dessa liminar para todo o território nacional poderá ocorrer, com o julgamento definitivo da ação civil pública, tendo em vista a questão já ter sido decidida mesmo que regionalmente (Rio Grande do Sul, Acre, Sergipe, Pernambuco e Mato Grosso) e o Conselho Nacional de Justiça ter recomendado aos tribunais a adoção de uma escuta especial (CNJ, 2010). Reforçando essa perspectiva, a tendência dos tribunais superiores é no sentido de decidir a sua obrigatoriedade, onde existir, à disposição, a sala e os equipamentos, não sendo apenas uma faculdade dos operadores do direito (Superior Tribunal de Justiça, 2012). Em razão da obrigatoriedade da nova metodologia, advém a obrigatoriedade da interdisciplinaridade, do diálogo entre os saberes, que possibilita a construção de estratégias para se garantir o direito das crianças e adolescentes.

Em uma revisão sobre o Depoimento Sem Dano, Brito e Parente (2012) encontraram pontos favoráveis e desfavoráveis à prática. Dentre os primeiros, as autoras citam: (a) facilitação da produção de provas e combate à impunidade; (b) garantia da criança de ser ouvida e obstar a repetição do relato e da vitimização; (c) propiciar o depoimento em um ambiente acolhedor, tornando o relato mais eficiente e de maneira pouco onerosa; (d) entrevista feita por profissionais qualificados; (e) é um método empregado em diversos países. Por outro lado, dentre os aspectos desfavoráveis, foram encontrados: (a) igualdade entre inquirição e escuta psicossocial, o que seria um desrespeito à ética do psicólogo e do assistente social; (b) privilégio da busca de provas para a punição do agressor, transformando o direito da criança em depor em obrigação; (c) evidenciaria o discurso da criança e ignoraria a possibilidade de falsas denúncias; (d) desconsideraria outros danos e colocaria a criança como corresponsável pela sanção do acusado; e, 
por último, (e) a ocorrência em outros países não significa sucesso (Brito \& Parente, 2012). Estudos que consideram os dois lados da questão e que, portanto, buscam uma solução unificada, sem estar vinculados a um ou outro partidarismo são fundamentais para o avanço do uso dessa metodologia. É necessário partir-se deste ponto, considerando que a experiência existe, está sendo implantada e fortalecida e que precisa ser estudada em todos os seus aspectos, corrigindo-se o que não estiver satisfatório e aperfeiçoando-se ainda mais o que estiver adequado.

Testemunhar em situações de abuso sexual, por certo, é uma tarefa estressante, especialmente se a criança tiver que repetir inúmeras vezes seu testemunho ou não tiver a presença de uma pessoa de sua confiança (Goodman et al., 1992). Entretanto, depor num tribunal pode ser uma experiência positiva, se alguns fatores estiverem favoráveis, como por exemplo: (a) se a criança estiver emocionalmente preparada; (b) se ela tiver um tratamento respeitoso e adequado à sua idade; (c) obtiver apoio; (d) receber serviços e proteção que se façam necessários após o julgamento; (e) for incentivada a depor; (f) se a família e os profissionais que lidam com a vítima o façam adequadamente e de forma a lidar com suas necessidades emocionais (Goodman, Ogle, Troxel, Lawler, \& Cordon, 2009). Estando estas condições asseguradas, o estresse característico de um depoimento pode ser atenuado, tornando-se menos traumático e revitimizador, e até mesmo, obtendo mais veracidade (Goodman et al., 2009).

O projeto do Depoimento Especial objetiva assegurar maior proteção às crianças e adolescentes que supostamente foram vítimas de violência sexual. Tendo o objetivo de proteção, pode se inferir que há, portanto, uma preocupação com a questão da infância como uma fase específica de desenvolvimento, que merece cuidados e atenção diferenciada. A participação da criança nas instâncias jurídicas deve ser pensada e para ela devem ser criadas alternativas que considerem essas especificidades desenvolvimentais. Além disso, considerar as características da própria violência e das dinâmicas familiares envolvidas no problema também constituem preocupações relevantes para o profissional entrevistador. Com esses conhecimentos de base, uma entrevista apropriada certamente é mais provável de ser realizada. Sob este ponto de vista, deve-se considerar ainda que o Direito necessita de outras disciplinas para bem administrar fenômenos que extrapolam o conhecimento jurídico, tais como o abuso sexual. Este é um evento que engloba diferentes áreas e saberes e a Justiça, sozinha, não pode dar conta adequadamente do problema. Por outro lado, a Psicologia detém conhecimentos significativos nesse sentido, especialmente relacionados à perspectiva do desenvolvimento humano, acolhimento, dinâmicas da violência e amplas abordagens de avaliação psicológica, incluindo as entrevistas como um dos principais métodos.

Como referido anteriormente, em diversos países, não é o psicólogo que atua na tarefa de entrevistar crianças. Outros profissionais podem também executar essa tarefa, como nos Estados Unidos, África do Sul, Austrália, Canadá, Cuba, Escócia, Franca, Índia, Inglaterra, Israel, Jordânia, Malásia, Noruega, Nova Zelândia, Suécia (B. R. Santos \& Gonçalves, 2009). Entretanto, mesmo nestes lugares, a recomendação mais comum é o uso da entrevista cognitiva, matéria estudada por psicólogos em todo o mundo. Considerando isso e a habilidade do psicólogo nesta área, Argentina, Brasil, Chile, Colômbia, Costa Rica, Equador, Espanha - Catalunha, Lituânia, Paraguai e Peru têm priorizado ou dado um lugar de destaque a este profissional para a condução da entrevista (B. R. Santos \& Gonçalves, 2009). Cabe enfatizar que no Brasil, os policiais nem sempre apresentam condutas adequadas ao lidar com situações de violência doméstica. Em delegacias especializadas, $o$ atendimento e a atenção a vítimas e familiares é diferenciado, sendo percebido como positivo no estudo realizado por S. S. Santos (2011). Entretanto, nas delegacias comuns, que são mais frequentemente encontradas no país, $\mathrm{o}$ atendimento e acolhimento podem ser precários, sem cuidado com a privacidade da vítima ou condições de trabalho adequadas para lidar com o problema. Além disso, há importantes diferenças entre policiais brasileiros e americanos ou europeus em se tratando tanto de demanda como de renda: no Brasil, a taxa de criminalidade é mais alta e o salário mais baixo, o que implica na condição de trabalhar mais por 
uma menor remuneração. Dessa forma, não se espera deste profissional que ele possa ter tempo para se dedicar a qualificar-se em uma área específica como o abuso sexual, uma vez que ele deve atuar em tantas outras áreas e problemas. Esse aspecto fortalece o envolvimento de profissionais graduados, como psicólogos e assistentes sociais, na condução de entrevistas em situações de ASI, uma vez que esses geralmente apresentam uma área de atuação mais limitada e, portanto, mais específica e qualificada.

Outro aspecto primordial que demonstra o quanto o psicólogo pode e deve contribuir para a área é abordado na legislação de regulamentação da profissão, que esclarece em seu artigo 13, inciso 2 "É da competência do Psicólogo a colaboração em assuntos psicológicos ligados a outras ciências" (Lei 4119, de 27 de agosto de 1962). Em seu Código de Ética, artigo 1, inciso j, está também presente a ideia de trabalhar com respeito, consideração e solidariedade com colegas e outros profissionais, quando este for solicitado, bem como sugerir (inciso k) serviços de outros psicólogos (CFP, 2005), se for o caso, como por exemplo, se o psicólogo não se sentir qualificado para tal tarefa. O psicólogo, neste sentido, não apenas pode colaborar com seu conhecimento e habilidade, mas a participação é um dever que cabe a este profissional. Além disso, o psicólogo, atuando no Depoimento Especial, pode impedir a revitimização da criança e trabalhar para promover a eliminação de violências, conforme previsto nos princípios fundamentais de seu Código de Ética (CFP, 2005), devendo, para isso, buscar aprimoramento profissional contínuo para atuar nesta nova metodologia com responsabilidade (CFP, 2005). A afirmação de que a atuação no Depoimento Especial não é um papel do psicólogo (Brito, 2008; CFP, 2010) não parece incluir ou considerar que a Psicologia possui uma diversidade de objetivos, instrumentos e papéis. Dessa forma, faz sentido pensar que essa nunca foi uma tarefa do psicólogo, mas que pode ser e pode ser qualificada. Entretanto, ela somente o será quando os profissionais se apropriarem dela, sugerirem mudanças e avançarem em direção ao progresso da técnica.

Das críticas que crucificam a metodologia podemos inferir mudanças que se fazem neces- sárias. Quando se pensa que buscar a verdade objetiva não é tarefa do psicólogo, podemos pensar que pode ser sim sua tarefa, na medida em que muitas abordagens teóricas são orientadas para adequar percepções distorcidas da realidade. Ou seja, uma verdade dita subjetiva pode não ser uma verdade real/material/histórica. Abordagens cognitivas, que têm ganhado espaço e resultados significativos buscam a verdade real/material/histórica no próprio contexto clínico, através de técnicas que fazem com que o sujeito busque informações com terceiros sobre aquilo que seria o objeto de sua percepção ou, por exemplo, técnicas que busquem que o indivíduo realize experimentos para confrontar suas percepções com a realidade (Beck, 1997). Psicologia cognitiva e Psicologia forense, portanto, são áreas orientadas à busca da verdade dos fatos e se aproximam da verdade buscada pelo sistema de justiça. Dessa forma, os psicólogos que se identificam com essas áreas podem atuar eticamente nessa questão sem interferir em valores pessoais ou identificações teóricas divergentes.

Outra crítica que pode ser objeto de mudança é a consideração de que na tarefa técnica do Depoimento Especial não há cuidados que seriam tradicionais da Psicologia, como encaminhar ou realizar ampla avaliação. Seria possível então, olhando para este aspecto, que o psicólogo, atuante no sistema de justiça, esteja associado a uma rede de cuidados, com contatos próximos com profissionais da rede de saúde e proteção. Com esses contatos, o psicólogo judiciário poderia fazer os encaminhamentos com facilidade e abertura, realizando também um acompanhamento breve antes e após o momento do depoimento. Além do encaminhamento, sugere-se maior tempo com a criança e com outros familiares ou pessoas próximas, no sentido de tornar o processo mais ampliado do que está sendo realizado no momento.

Do estudo de Brito e Pereira (2012), podemos observar a crítica de que o Depoimento Especial tem correspondido muito mais às expectativas do sistema jurídico do que da Psicologia. As autoras demonstram, através de estudo empírico, que a valorização do depoimento infantil tem se dado a partir da inexistência de outras provas, do baixo número de condenações e da consideração 
de que os depoimentos são consistentes e sólidos, dos quais se presume veracidade. As autoras encontraram também que com a prerrogativa do Depoimento Especial, o valor das provas materiais ficou em segundo plano, mesmo em situações em que houve comprovação do abuso a partir do exame de corpo delito. Com isso, pode-se sugerir que exista maior cuidado por parte dos trabalhadores do sistema de justiça, que se considere com maior imparcialidade o depoimento, no sentido de questionar também a veracidade e qualidade destes e também que não transfiram o papel decisório para as crianças e adolescentes: a decisão é da figura jurídica e não da vítima.

Diante dessas considerações, cabe, aos profissionais envolvidos nessa tarefa e outros que se interessam por ela, buscar a qualificação do Depoimento Especial, em todos os seus aspectos, sejam eles técnicos, tecnológicos, éticos, relacionados à equipe ou à instituição da justiça. Há a necessidade premente de se investigar o que de fato ocorre, com entrevistadores e entrevistados, além da equipe de justiça, como defensores, promotores e juízes, no sentido de buscar as percepções daqueles que estão de fato realizando este trabalho. Como é trabalhar com Depoimento Especial, como tem sido o contato com as vítimas, quais são os aspectos positivos e negativos, vivenciados pelos profissionais e entrevistados: esses devem ser objeto de investigação empírica nos próximos anos, para que essa complexa área de interface entre Psicologia e Direito possa ser melhor conhecida e a metodologia realmente qualificada.

Dessa forma, sugere-se que a crítica seja transformada em mudança e que posições contrárias, por vezes tão calorosas, conduzam ao aperfeiçoamento. Certamente, o maior benefício e proteção às crianças e adolescentes vítimas não reside no fato de simplesmente defendermos arduamente argumentos e permanecermos firmes em um determinado posicionamento. Estaremos atuando na proteção quando pudermos avançar, trocar conhecimentos e compartilhar informações, não na perspectiva de uma ciência ou área específica, mas num conjunto interdisciplinar que precisa se fortalecer para verdadeiramente proteger.

\section{Referências}

Beck, J. (1997). Terapia cognitiva: Teoria e prática. Porto Alegre, RS: Artmed.

Brito, L. M. T. (2008). Diga-me agora... o depoimento sem dano em análise. Psicologia Clínica, 20(2), 113-125.

Brito, L. M. T., \& Parente, D. C. (2012). Inquirição judicial de crianças: Pontos e contrapontos. Psicologia \& Sociedade, 24(1), 178-186.

Brito, L. M. T., \& Pereira, J. B. (2012). Depoimento de crianças: Um divisor de águas nos processos judiciais? Psico-USF, 17(2), 285-293.

Children Justice Center. (2009). Procedural guidelines for interagency response to child sexual abuse and serious physical abuse in Hawaii County. Hawaii, United States: Author.

Código de Processo Civil. (1973). Lei 5.869. Brasília, DF: Presidência da República. Recuperado em 02 de junho de 2013, de http://www.planalto. gov.br/ccivil_03/leis/L5869.htm

Código de Processo Penal. (1941). Decreto-Lei 3.689. Brasília, DF: Presidência da República. Recuperado em 02 de junho de 2013, de http://www.planalto.gov.br/ccivil_03/decreto-lei/del3689.htm

Conselho Federal de Psicologia. (2005). Código de Ética Profissional do Psicólogo. Recuperado em 02 de junho de 2013, de http://site.cfp.org.br/ wp-content/uploads/2012/07/codigo_etica.pdf

Conselho Federal de Psicologia. (2010). Resolução CFP 010/2010. Recuperado em 02 de junho de 2013, de http://site.cfp.org.br/wp-content/uploads/2010/07/resolucao2010_010.pdf

Conselho Federal de Psicologia. (2012). Escuta de crianças e adolescentes envolvidos em situação de violência: Histórico. Recuperado em 11 de dezembro de 2012, de http://site.cfp.org.br/wpcontent/uploads/2012/07/Hist $\%$ C3\%B3rico-Escuta-de-Crian $\% \mathrm{C} 3 \%$ A 7as-e-Adolescentes.pdf

Conselho Federal de Serviço Social. (2009). Resolução CFESS 554/2009. Recuperado em 02 de junho de 2013, de http://www.cfess.org.br/ arquivos/Resolucao_CFESS_554-2009.pdf

Conselho Nacional de Justiça. (2010). Recomendação 33 , de 23 de novembro de 2010. Diário da Justiça, 215/2010, pp. 33-34. Recuperado em 02 de julho de 2013, de http://www.cnj.jus.br/atos-administrativos/atos-da-presidencia/322-recomendacoes-do-conselho/12114-recomendacao-no-33 
Constituição da República Federativa do Brasil de 1988. (1988). Brasília, DF: Presidência da República. Recuperado em 02 de junho de 2013, de http://www.planalto.gov.br/ccivil_03/constituicao/constituicao.htm

Cross, T. P., Jones, L. M., Walsh, W. A., Simone, M., \& Kolko, D. (2007). Child forensic interviewing in Children's Advocacy Center: Empirical data on a practice model. Child Abuse \& Neglect, 31, 1031-1052.

Daltoé Cezar, J. A. (2007). Depoimento sem dano: Uma alternativa para inquirir crianças e adolescentes nos processos judiciais. Porto Alegre, RS: Livraria do Advogado.

Decreto 99.710. (1990). Promulga a Convenção sobre os Direitos da Criança. Brasília, DF: Presidência da República. Recuperado em 02 de junho de 2013, de http://www.planalto.gov.br/ccivil_03/ decreto/1990-1994/D99710.htm

Dobke, V. (2001). Abuso sexual: A inquirição das crianças - Uma abordagem interdisciplinar. Porto Alegre, RS: Ricardo Lenz Editor.

Dobke, V. M., Santos, S. S., \& Dell'Aglio, D. D. (2010). Abuso sexual intrafamiliar: Da notificação ao depoimento no contexto processual-penal. Temas em Psicologia, 18(1), 167-176.

El-Sayed Aboul-Hagag, K., \& Hamed, A. F. (2012). Prevalence and pattern of child sexual abuse reported by cross sectional study among the University students Sohag University, Egypt. Egyptian Journal of Forensic Sciences, 2(3), 89-96.

Estatuto da Criança e do Adolescente. (1990). Lei 8.069. Brasília, DF: Presidência da República. Recuperado em 02 de junho de 2013, de http:// www.planalto.gov.br/ccivil_03/leis/L8069.htm

Finnila-Tuohimaa, K., Santilla, P., Sainio, M., Niemi, P., \& Sandnabba, K. (2009). Expert judgments in cases of alleged child sexual abuse: Clinician's sensitivity to suggestive influences, pre-existing beliefs and base rate estimates. Scandinavian Journal of Psychology, 50, 129-142.

Goodman, G. S., Ogle, C. M., Troxel, N., Lawler, M. J., \& Cordon, I. M. (2009). Crianças vítimas no sistema judiciário: Como garantir a precisão do testemunho e evitar a revitimização. In B. R. Santos \& I. B. Gonçalves, Depoimento sem medo: Culturas e práticas não revitimizantes Uma cartografia das experiências de tomada de depoimento especial de crianças e adolescentes (pp. 21-34). São Paulo, SP: Childhood Brasil.
Goodman, G. S., Taub, E. P., Jones, D. P., England, P., Port, L. K., Rudy, L., \& Prado, L. (1992). Testifying in criminal court: Emotional effects on child sexual assault victims. Monographs of the Society for Research in Child Development, 57(5), 1-142.

Goodman, G. S., Tobey, A., Batterman-Faunce, J., Orcutt, H., Thomas, S., Shapiro, C., \& Sachsenmaier, T. (1998). Face-to-face confrontation: Effects of closed-circuit technology on children's eyewitness testimony and jurors' decisions. Law and Human Behavior, 22, 165-302.

Guedes, L. T. (2012). A busca da verdade real e o direito de não produzir prova contra si mesmo. Revista Jus Navigandi, 17(3282), 1-4.

Hanna, K., Davies, E., Crothers, C., \& Henderson, E. (2012). Child witnesses' access to alternative modes of testifying in New Zealand. Psychiatry, Psychology \& Law, 19(2), 184-197.

Lei 12.010. (2009). Dispõe sobre adoção. Brasília, DF: Presidência da República. Recuperado em 02 de junho de 2013, de http://www.planalto.gov.br/ccivil_03/_ato2007-2010/2009/lei/ 112010.htm

Lei 4119, de 27 de agosto de 1962. (1962). Dispõe sobre os cursos de formação em Psicologia e regulamenta a profissão de psicólogo. Brasília, DF: Ministério da Educação e Cultura.

Lima, J. S., \& Deslandes, S. F. (2011). A notificação compulsória do abuso sexual contra crianças e adolescentes: Uma comparação entre os dispositivos americanos e brasileiros. Interface: Comunicação, Saúde, Educação, 15(38), 819-832.

McAulif, B. D., \& Kovera, M. B. (2012). Do jurors get what they expect? Traditional versus alternative forms of children's testimony. Psychology, Crime \& Law, 18(1), 27-47.

Miller-Perrin, C. L., \& Perrin, R. D. (2013). Child maltreatment: An introduction. Los Angeles, CA: Sage Publications.

Ministério da Saúde. (2001). Portaria MS/GM $n$. 1.968, de 25 de outubro de 2001. Dispõe sobre a notificação, às autoridades competentes, de casos de suspeita ou de confirmação de maus-tratos contra crianças e adolescentes atendidos nas entidades do Sistema Único de Saúde. Diário Oficial da União, 206, Seção 1, p. 86.

Myers, J. E. B. (2006). Child protection in America: Past, present and future. New York: Oxford University Press. 
National Children's Alliance. (2012). Child Advocacy: Putting the needs of child abuse victims first. Retrieved October 26, 2012. from http://www. nationalchildrensalliance.org/

Oliveira, E. P. (2009). Curso de processo penal (11. ed.). Rio de Janeiro, RJ: Lumens Juris.

Paolucci, E. O., Genuis, M. L., \& Violato, C. (2001). A meta-analysis of the published research on the effects of child sexual abuse. The Journal of Psychology, 135(1), 17-36.

Pereda, N., Guilera, G., Forns, M., \& Gomez-Benito, J. (2009). The prevalence of child sexual abuse in community and student samples: A meta analysis. Clinical Psychological Review, 29, 328-338.

Rios, A. (2009). Violência infantil: Levantamento de perícias realizadas em crianças e adolescentes vítimas de violência doméstica e sexual no período entre 2007 e 2009 (Trabalho de conclusão do Curso de Especialização em Psiquiatria, Centro de Estudos José de Barros Falcão, Universidade Federal de Ciências da Saúde de Porto Alegre, RS, Brasil).

Saliba, O., Garbin, C. A. S., Garbin, A. J. I., \& Dossi, A. P. (2007). Responsabilidade do profissional de saúde sobre a notificação de casos de violência domestica. Revista de Saúde Pública, 41(3), 472-477.

Sanchez-Meca, J., Rosa-Alcázar, A. I., \& López-Soler, C. (2011). The psychological treatment of sexual abuse in children and adolescents: A meta analysis. International Journal of Clinical and Health Psychology, 11(1), 67-93.

Santos, B. R., \& Gonçalves, I. B. (2009). Depoimento sem medo: Culturas e práticas não revitimizantes - Uma cartografia das experiências de tomada de depoimento especial de crianças $e$ adolescentes. São Paulo, SP: Childhood Brasil.

Santos, S. S. (2011). Uma análise do contexto de revelação e notificação do abuso sexual: A percepção de mães e adolescentes vítimas (Tese de doutorado, Programa de Pós-Graduação em Psicologia, Universidade Federal do Rio Grande do Sul, Porto Alegre, RS, Brasil).
Scott, J. (1994). Child witnesses: An Australian perspective. Child Abuse Review, 3(3), 179-192.

Secretaria de Direitos Humanos da Presidência da República. (2010). Disque Denúncia NacionalDDN 100: Relatório Janeiro-Junho 2010. Brasília, DF: Subsecretaria Nacional de Direitos da Criança e do Adolescente. Recuperado em 27 de julho de 2010, de http://www1.direitoshumanos. gov.br/spdca/exploracao_sexual/ Acoes_PPCAM/disque_denuncia

Senado Federal. (2007). Projeto de Lei da Câmara 035/2007. Brasília, DF: Autor. Recuperado em 02 de junho de 2013, de http://www. senado.gov.br/atividade/materia/getPDF. asp?t=39687\&tp=1

Stoltenborgh, M., Van Ijzendoorn, M. H., Euser, E. M., \& Bakermans-Kranenburg, M. J. (2011). A global perspective on child sexual abuse: Metaanalysis of prevalence around the world. Child Maltreatment, 16(2), 79-101.

Superior Tribunal de Justiça. (2012). Habeas Corpus 246369. Recuperado em 07 de fevereiro de 2013, de http://www.jusbrasil.com.br/diarios/41232810/stj-08-10-2012-pg-224/pdfView

Trickett, P. K., Negriff, S., Ji, J., \& Peckins, M. (2011). Child maltreatment and adolescent development. Journal of Research on Adolescence, 21(1), 3-20.

World Health Organization. (2006). Preventing child maltreatment: A guide to taking action and generating evidence. Geneva, Switzerland: Author.

World Health Organization. (2010). Child maltreatment. Retrieved September 14, 2012, from http://www.who.int/mediacentre/factsheets/ fs150/en/index.html
Recebido: $28 / 2 / 2013$

$1^{a}$ revisão: $15 / 06 / 2013$

Aceite final: $24 / 06 / 2013$ 